\title{
Portbail - Église Notre-Dame
}

$n^{\circ} 3470$

\section{Florian Bonhomme}

\section{(2) OpenEdition \\ 12 Journals}

Édition électronique

URL : http://journals.openedition.org/adlfi/16765

ISSN : 2114-0502

Éditeur

Ministère de la culture

Référence électronique

Florian Bonhomme, « Portbail - Église Notre-Dame », ADLFI. Archéologie de la France - Informations [En ligne], Basse-Normandie, mis en ligne le 26 février 2016, consulté le 19 avril 2019. URL : http:// journals.openedition.org/adlfi/16765

Ce document a été généré automatiquement le 19 avril 2019

(C) Ministère de la Culture et de la Communication, CNRS 


\title{
Portbail - Église Notre-Dame
}

$n^{\circ} 3470$

\author{
Florian Bonhomme
}

Lien Atlas (MCC) :

http://atlas.patrimoines.culture.fr/atlas/trunk/index.php?

ap_theme=DOM_2.01.02\&ap_bbox=-1.746;49.325;-1.638;49.383

1 Préalablement à la réfection des façades de l'église Notre-Dame et de l'étanchéité du clocher, un diagnostic a été réalisé sur les élévations de l'église.

2 La première mention de Portbail est celle d'un portus au $\mathrm{IX}^{\mathrm{e}} \mathrm{s}$. Mais c'est la mention d'une abbatia à plusieurs reprises au $\mathrm{XI}^{\mathrm{e}} \mathrm{s}$. qui retient ici l'attention, puisqu'un prieuré est bien attesté à partir $\mathrm{du} \mathrm{XI}^{\mathrm{e}} \mathrm{s}$. à quelques mètres au nord-ouest de l'église. Rappelons que l'église se trouve sur une position topographique particulière, puisqu'elle est placée en limite de l'estran, au bord du havre de Portbail.

3 Après la fouille du baptistère par Michel de Boüard en 1956, deux autres fouilles ont eu lieu, dans la moitié sud-ouest de la nef de l'église Notre-Dame, entre 1968 et 1974. Ces deux opérations avaient mis au jour un système d'hypocauste et de praefurnium daté du $\mathrm{II}^{\mathrm{e}}$ s. apr. J.-C. Le diagnostic a pu confirmer la présence exceptionnelle de maçonneries de cette période dans les élévations, en particulier pour la nef. L'orientation de l'église, qui diffère d'environ $45^{\circ}$ par rapport à l'orientation chrétienne classique, est héritée des bâtiments antiques réutilisés et conservée tout au long du Moyen Âge.

4 Le diagnostic a également permis de mettre en évidence la présence de maçonneries appartenant au haut Moyen Âge, avec notamment des parements caractéristiques en opus spicatum pour la nef. Cela vient appuyer les argumentations historiques qui tentent de démontrer la présence d'un établissement religieux très tôt à Portbail (période mérovingienne?).

5 Vraisemblablement à la fin $\mathrm{du} \mathrm{XI}^{\mathrm{e}}$ s., un important programme architectural voit la reconstruction quasiment complète de l'église, en ne conservant qu'une partie de la nef. Toutefois, les transepts et le clocher n'ont pas pu être caractérisés lors de l'intervention. 
Si quelques modifications postérieures ont eu lieu avec l'agrandissement d'un certain nombre de baies, c'est véritablement à la fin du Moyen Âge que l'église se trouve à nouveau modifiée. Les transepts disparaissent, ainsi que le clocher non localisé, pour laisser la place à une chapelle à deux travées au nord-ouest et un clocher massif au sudest, dont le rez-de-chaussée servira également de chapelle. Enfin, un porche est ajouté à l'entrée, contre le mur gouttereau sud-est. Il faut également signaler la présence des vestiges d'une litre funéraire à l'intérieur comme à l'extérieur.

Différentes utilisations du clocher ont pu être notées, en particulier avec la présence de guetteurs depuis au moins le dernier tiers $d u X V_{I I}{ }^{e} s$. et très certainement après, mis en place à l'occasion des différentes guerres du règne de Louis XIV. Au XIX ${ }^{\mathrm{e}} \mathrm{s}$., peut-être avant, au bas Moyen Âge, le clocher fut utilisé comme amers (point de repère terrestre pour la navigation maritime près des côtes), peint en blanc. Un feu de couleur rouge y a également été installé à la même période, couplé à un second de couleur blanche à l'entrée du havre. Contrairement à ce qu'ont pu écrire plusieurs auteurs, la fortification du clocher n'a toujours été qu'une apparence. L'aspect trapu, les merlons et créneaux sans mâchicoulis et les fausses ouvertures de tirs n'ont, en substance, jamais eu d'utilité, hormis pour la surveillance du trafic maritime local.

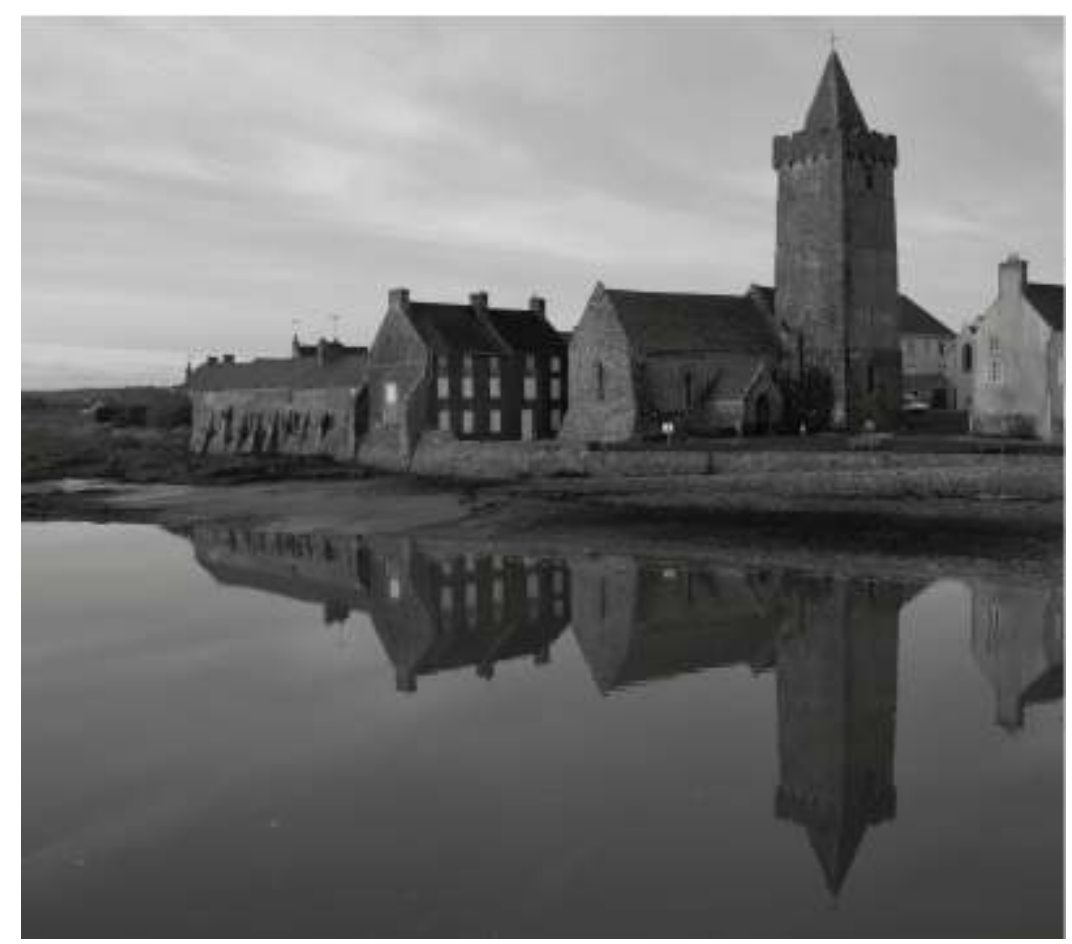

Fig. 01

Église Notre-Dame et prieuré sur les bords de l'estran du havre de Portbail Cliché F. Bonhomme, Inrap 
INDEX

Index géographique : Basse-Normandie, Manche (50), Portbail operation Diagnostic (EV)

Index chronologique : Moyen Âge

Mots-clés : chapelle, maçonnerie, clocher

\section{AUTEURS}

\section{FLORIAN BONHOMME}

Inrap 